\title{
Association Between Grading of Oral Submucous Fibrosis With Frequency and Consumption of Areca Nut and Its Derivatives in a Wide Age Group: A Multi-centric Cross Sectional Study From Karachi, Pakistan
}

\author{
Mervyn Hosein, Sidra Mohiuddin, Nazish Fatima \\ Department of Oral and Maxillo-Facial Surgery, Ziauddin College of Dentistry, Ziauddin University, Karachi, Pakistan
}

\begin{abstract}
Background: Oral submucous fibrosis (OSMF) is a chronic, premalignant condition of the oral mucosa and one of the commonest potentially malignant disorders amongst the Asian population. The objective of this study was to investigate the association of etiologic factors with: age, frequency, duration of consumption of areca nut and its derivatives, and the severity of clinical manifestations. Methods: A cross-sectional, multi centric study was conducted over 8 years on clinically diagnosed OSMF cases $(n=765)$ from both public and private tertiary care centers. Sample size was determined by World Health Organization sample size calculator. Consumption of areca nut in different forms, frequency of daily usage, years of chewing, degree of mouth opening and duration of the condition were recorded. Level of significance was kept at $P \leq 0.05$.

Results: A total of 765 patients of OSMF were examined, of whom $396(51.8 \%)$ were male and $369(48.2 \%)$ female with a mean age of 29.17 years. Mild OSMF was seen in 61 cases (8.0\%), moderate OSMF in 353 (46.1\%) and severe OSMF in 417 (54.5\%) subjects. Areca nut and other derivatives were most frequently consumed and showed significant risk in the severity of OSMF $(P \leq 0.0001)$. Age of the sample and duration of chewing years were also significant $(P=0.012)$.

Conclusions: The relative risk of OSMF increased with duration and frequency of areca nut consumption especially from an early age of onset.
\end{abstract}

(J Cancer Prev 2015;20:216-222)

Key Words: Oral submucous fibrosis, Areca nut, Betel quid, Clinical grading

\section{INTRODUCTION}

Oral submucous fibrosis (OSMF), one of the most chronic and premalignant conditions of the oral mucosa was initially described by Schwartz in 1952, and further documented by Pindborg in 1996..$^{1-3}$ OSMF is one of the commonest potentially malignant disorders amongst the Asian population. ${ }^{4}$ In 1956, Paymaster ${ }^{5}$ first described its malignant transformation. Arakeri and Brennan ${ }^{6}$ estimated the rate of malignant transformation to be $7 \%$ to $30 \%$ while other studies have reported between $3 \%$ to
$19 \% .^{7,8}$ An established etiological factor is consumption of areca nut, the fourth most common social drug after nicotine, ethanol and caffeine. ${ }^{9}$

OSMF is usually seen in populations (particularly Indians and Pakistanis) of the South Asian states and in Taiwanese. Some other regional clustering has been noted documenting that both sexes are equally affected with maximal occurrence in the second and third decades of life. ${ }^{6}$ A few studies have concluded that OSMF is rarely found in a pediatric age group..$^{10,11}$

Areca nut is chewed for a variety of reasons: as a stress reliever,

Received August 3, 2015, Revised August 27, 2015, Accepted August 28, 2015

Correspondence to: Mervyn Hosein

Department of Oral and Maxillo-Facial Surgery, Ziauddin College of Dentistry, Ziauddin University, 4/B, Shahrah-e-Ghalib, Block 6, Clifton, Karachi-757600, Pakistan

Tel: +92-21-34531697, Fax: +92-21-35862940, E-mail: mmh5617@gmail.com

Copyright (ㄷ) 2015 Korean Society of Cancer Prevention

(c) This is an Open Access article distributed under the terms of the Creative Commons Attribution Non-Commercial License (http://creativecommons.org/licenses/by-nc/4.0) which permits unrestricted non-commercial use, distribution, and reproduction in any medium, provided the original work is properly cited. 
mouth freshener, concentration improver and as a digestive after meals. Being an addictive substance its withdrawal symptoms include mood swings, anxiety and irritability, loss of concentration, sleep disturbance and craving. ${ }^{6}$ The pathogenesis is believed to involve a juxta-epithelial inflammatory reaction leading to fibrosis, probably due to an increased cross-linking of collagen through up-regulation of lysyl oxidase activity. These effects of areca nut cause an increase in collagen production (stimulated by the alkaloid arecoline) with decreased collagen degradation resulting in fibrosis. OSMF is now considered a collagen metabolic disorder. ${ }^{12,13}$ Studies have also documented other possible etiologic factors, including capsaicin in chilies and deficiencies of iron, zinc, and other essential vitamins. ${ }^{14}$

A large variety of easily accessible areca nut derivatives are available nowadays, particularly in the form of supari, pan masala and gutka. The basic ingredient is areca nut with addition of natural and artificial perfuming, flavoring materials, chewing tobacco, catechu, cardamom, lime etc. ${ }^{8}$ Combinations are packaged making them portable, less expensive, and widely available in addition to enhancing their shelf-life. They also are exported to countries where Asian migrants live. ${ }^{15}$

Globally up to 600 million chewers are reported however, the disease is predominantly found in Asian-Pacific countries. ${ }^{16}$ Regional variations in the characteristics of OSMF were studied in two districts in India. In Pune, the soft palate, uvula and retromolar areas were affected significantly more often than in Ernakulum. Studies from India cite OSMF as a public health problem found mostly in populations of low socioeconomic status. ${ }^{12}$ Local literature has revealed a rising prevalence among school children resulting from significantly increased consumption of areca nut. ${ }^{17-19}$

There is limited local data on OSMF with reported studies based on small sample sizes, or in specific age groups, like school going children, and single center based. The current cross sectional study is based on a larger sample size $(n=765)$ across a wide age range (10 -75 years). Moreover, it is a multi-centric study with samples from both private and public tertiary healthcare facilities. The objective was to investigate associations of areca nut and its derivatives; frequency per day; years of chewing; and brands of different commercially available packaged areca nut, with the clinical grading of OSMF.

\section{MATERIALS AND METHODS}

This is a cross-sectional, multicentric study with clinically diagnosed cases of OSMF $(n=765)$ from both public and private tertiary care hospitals and clinics over a period of eight years. All the subjects were examined and documented by the corresponding author.

Sample size was determined by World Health Organization (WHO) sample size calculator by estimating a population proportion with specified absolute precision, keeping 95\% CI, 0.05 anticipated population proportions, 0.02 precision and 5\% margin of error.

Clinical details included age, gender, clinical grading of OSMF, associated habits of eating plain or packaged areca nut alone as well as its derivatives in the form of betel quid (paan) with or without tobacco, naswar (moist powdered tobacco snuff), etc. The consumption of areca nut in different commercially available packaged forms; frequency per day; years of chewing; sites of the condition - either bilateral or unilateral; as well as the duration of the condition, were recorded. Assessment of clinical grading was based on the classification proposed by Bose and Balan in 2007; group A had mild involvement, group B moderate and group $C$ were severely affected. ${ }^{20}$

Clinically, group A presents with occasional symptoms: pallor, vesicle formation, possibly one or two solitary palpable bands, mild loss of elasticity of mucosa, little tongue involvement with protrusion beyond the vermillion border and an inter-incisal opening of $3 \mathrm{~cm}$ or more. Group B patients present with complaints of soreness or burning mucosa or increased sensitivity to chillies, diffuse involvement of the mucosa, blanching of the buccal mucosa, inelastic fibrous bands with mouth opening of 1.5 to $3.0 \mathrm{~cm}$ and variably limited tongue movement. Patients in group C present with severe symptoms: blanched, opaque, mucosa, broad palpable fibrous bands, mouth opening less than $1.5 \mathrm{~cm}$ and tongue depapillation with restricted mobility.

Study population comprised of both genders with ages ranging from 10 to 75 years old. Dependent variable was the clinical grading of OSMF while independent variables were frequency of consumption per day, duration of chewing, duration of condition, eating habits, age and gender of the study subjects.

Data entry and analysis was performed using SPSS ver. 17 (SPSS Inc., Chicago, IL, USA). Frequencies and percentages of qualitative variables, with mean and standard deviations of quantitative variables were analyzed. Chi-square test was used to find associations among variables as well as OR calculated by using multinomial logistic regression in between dependent and independent variables. Level of significance was kept at $P \leq 0.05$.

\section{RESULTS}

Of all the OSMF cases $(n=765)$ examined 396 patients $(51.8 \%)$ 
were males and 369 patients (48.2\%) were females. The minimum age reported was 10 years and maximum 75 years with a mean age of 29.17 years. Percentage of $8.0(n=61)$ were clinically graded in group A, 46.1\% $(n=353)$ in group $B$ and $45.9 \%(n=351)$ with severe OSMF in group $\mathrm{C}$.

Percentage of $88.9(n=680)$ had inter-incisal openings ranging from 0 to $31 \mathrm{~mm}$ and only $11.1 \%(\mathrm{n}=85)$ ranged from 32 to 62 mm. Percentage of $95.0(n=727)$ of the subjects had bilateral

Table 1. Descriptive analysis of oral submucous fibrosis among study subjects (total number $=765$ )

\begin{tabular}{|c|c|}
\hline Variable & Frequency \\
\hline \multicolumn{2}{|l|}{ Gender } \\
\hline Male & $396(51.8)$ \\
\hline Female & $369(48.2)$ \\
\hline \multicolumn{2}{|l|}{ Age (yr) } \\
\hline $10-20$ & $258(33.7)$ \\
\hline $21-30$ & $238(31.1)$ \\
\hline $31-40$ & $147(19.2)$ \\
\hline $41-50$ & $80(10.5)$ \\
\hline $51-60$ & $26(3.4)$ \\
\hline $61-75$ & $16(2.1)$ \\
\hline \multicolumn{2}{|l|}{ Incisor opening (mm) } \\
\hline $0-31$ & $680(88.9)$ \\
\hline $32-62$ & $85(11.1)$ \\
\hline \multicolumn{2}{|l|}{ Location of condition } \\
\hline Right side & $19(2.5)$ \\
\hline Left side & $19(2.5)$ \\
\hline Bilateral & $727(95.0)$ \\
\hline \multicolumn{2}{|l|}{ Etiology } \\
\hline Betel nut & $417(54.5)$ \\
\hline Betel quid without tobacco & $112(14.6)$ \\
\hline Betel quid with tobacco & $200(26.1)$ \\
\hline Naswar & $17(2.2)$ \\
\hline Other chew types & $3(0.4)$ \\
\hline None & $16(2.1)$ \\
\hline \multicolumn{2}{|l|}{ Frequency (per day) } \\
\hline $1-5$ & $95(12.4)$ \\
\hline $6-10$ & $177(23.1)$ \\
\hline $11-15$ & $84(11.0)$ \\
\hline $16-20$ & $77(10.1)$ \\
\hline $21-26$ & $241(31.5)$ \\
\hline $26-30$ & $90(11.8)$ \\
\hline Countless & $1(0.1)$ \\
\hline \multicolumn{2}{|l|}{ Duration of chew (yr) } \\
\hline $0-10$ & $526(68.8)$ \\
\hline $11-20$ & $176(23.0)$ \\
\hline $21-30$ & $49(6.4)$ \\
\hline $31-40$ & $12(1.6)$ \\
\hline $41-50$ & $2(0.3)$ \\
\hline \multicolumn{2}{|l|}{ Duration of condition (yr) } \\
\hline$<20$ & $751 \quad(98.2)$ \\
\hline $20-40$ & $14(1.8)$ \\
\hline
\end{tabular}

Values are presented as number (\%).
OSMF involvement. Only 5.0\% $(\mathrm{n}=38)$ had unilateral fibrosis.

Majority of the sample $54.5 \%(n=417)$ ate only plain or packaged areca nut, followed by $26.1 \%(n=200)$ who consumed betel quid (paan) with tobacco. Percentage of $14.6(n=112)$ used betel quid (paan) without tobacco, while $2.2 \%(n=17)$ used naswar and only a few $0.4 \%(n=3)$ consumed other chew types.

Commercially packaged areca nut was consumed by $31.5 \%$ ( $n=$ 241) with a frequency of 21 to 26 packets per day followed by $23.1 \%$ $(n=177)$ consuming 6 to 10 packets. Percentage of $68.8(n=526)$ reported less than ten years of chewing experience; $23.0 \%(\mathrm{n}=$ 176) had 11 to 20 years; $6.4 \%(n=49), 1.6 \%(n=12)$ and $0.3 \%(n=$ 2) had 21 to 30 years, 31 to 40 years and 41 to 50 years of chewing experience, respectively. Percentage of $98.2(n=751)$ had OSMF for less than 20 years while $1.8 \%(n=14)$ had the condition for over 20 years (Table 1 ).

Multinomial logistic regression was used to find the odds ratio among the dependent and independent variables. Significant association was found for mouth opening with clinical grading of OSMF (OR $=0.848,95 \% \mathrm{CI} 0.815-0.883, P<0.0001$ ) indicating that as grading of OSMF moves towards severity, mouth opening decreases. The association of frequency of chewing areca nut and other derivatives with clinical grading of OSMF was also found to be significant (OR $=1.557,95 \% \mathrm{CI} 1.444-1.678, P<0.0001$ ) indicating an increased risk of severity of OSMF with increase in frequency per day. However, age of the sample, years of chewing and duration of disease were found to be statistically insignificant with no effect on severity of OSMF (Table 2).

In the descriptive analysis of areca nut consumed in packaged, as well as in other forms of betel quid, with or without tobacco, $54.5 \%(n=417)$ of subjects gave a history of preferentially

Table 2. Association between clinical grading of OSMF with different variables

\begin{tabular}{lrlll}
\hline Clinical grading of OSMF & Coefficient & $P$-value & OR & \multicolumn{1}{c}{$95 \% \mathrm{CI}$} \\
\hline Moderate & & & & \\
Age of the sample & 0.015 & 0.223 & 1.01 & $0.991-1.039$ \\
Frequency per day & 0.123 & $0.000^{*}$ & 1.13 & $0.954-1.078$ \\
Chewing years & 0.005 & 0.828 & 1.00 & $0.964-1.047$ \\
Mouth opening & -0.077 & $0.000^{*}$ & 0.92 & $0.899-0.955$ \\
$\quad$ Duration of lesion & 0.014 & 0.642 & 1.015 & $0.954-1.078$ \\
Severe & & & & \\
Age of the sample & 0.026 & 0.077 & 1.026 & $0.997-1.057$ \\
Frequency per day & 0.442 & $0.000 *$ & 1.557 & $1.444-1.678$ \\
Chewing years & 0.027 & 0.283 & 1.028 & $0.978-1.080$ \\
Mouth opening & -0.165 & $0.000^{*}$ & 0.848 & $0.815-0.883$ \\
Duration of lesion & 0.031 & 0.423 & 1.031 & $0.956-1.112$ \\
\hline
\end{tabular}

Multinomial logistic regression test (*statistically significant). OSMF, oral submucous fibrosis. ${ }^{a}$ In reference with mild category. 
consuming one of three specific packaged local brands. Brand A was consumed by $41.6 \%(n=318)$, brand B by $8.4 \%(n=64)$ and brand $\mathrm{C}$ by $2.8 \%(\mathrm{n}=21)$. A small number, $2.2 \%(\mathrm{n}=17)$ had no specific packaged brand preference.

Percentage of $40.4(n=309)$ used areca nut in other forms (e.g., betel quid and its variants). Only $4.7 \%(n=36)$ claimed to have no habit of using areca nut in any form. Statistically insignificant difference was found among areca nut consumption of individual brands as compared with usage in other combinations confirming that areca nut, in any form, promotes OSMF.

Statistically significant difference was found between consumption of areca nut alone, betel quid with tobacco and other derivatives (moderate OSMF cases, $n=176$ ) and betel quid without tobacco (severe OSMF cases, $\mathrm{n}=167$ ) with clinical grading of OSMF by applying Z-comparing 2 population proportion $(P \leq$ 0.0001) (Table 3).

Statistically significant difference $(P \leq 0.012)$ was found between ages of the sample and chewing years, determined by applying chi-square test. Majority among the 10 to 20 years of age $(n=187)$ consumed only areca nut followed by those in the 21 to 30 age group $(n=170)$. The least number of cases $(n=78)$ were between the ages of 41 to 75 years (Table 4).

Table 3. Association of three main etiological factors with clinical grading of OSMF

\begin{tabular}{|c|c|c|c|c|}
\hline \multirow{2}{*}{$\begin{array}{l}\text { Grading } \\
\text { of OSMF }\end{array}$} & \multicolumn{3}{|c|}{ Main etiological risk habit } & \multirow[b]{2}{*}{$P$-value } \\
\hline & $\begin{array}{c}\text { Areca } \\
\text { nut }\end{array}$ & $\begin{array}{c}\text { Betel quid } \\
\text { without tobacco }\end{array}$ & $\begin{array}{l}\text { Betel quid with tobacco } \\
\text { and other derivatives }\end{array}$ & \\
\hline Mild & 36 & 4 & 19 & $0.00 *$ \\
\hline Moderate & 120 & 46 & 176 & $0.00 *$ \\
\hline Severe & 97 & 167 & 68 & $0.00 *$ \\
\hline
\end{tabular}

OSMF, oral submucous fibrosis. Z-test comparing 2 population proportion (*statistically significant).

Table 4. Association between age of the sample with duration of chewing years

\begin{tabular}{crrrc}
\hline \multirow{2}{*}{$\begin{array}{c}\text { Duration of chew } \\
\text { (yr) }\end{array}$} & \multicolumn{4}{c}{ Age (yr) } \\
\cline { 2 - 5 } & $10-20$ & $21-30$ & $31-40$ & $41-75$ \\
\hline $0-10$ & 187 & 170 & 91 & 78 \\
$11-20$ & 48 & 51 & 40 & 37 \\
$21-30$ & 9 & 11 & 13 & 16 \\
$31-40$ & 4 & 5 & 2 & 1 \\
$41-50$ & 0 & 0 & 1 & 1 \\
$P$-value & - & $0.012^{*}$ & - & - \\
\hline
\end{tabular}

Chi-square test (*statistically significant).

\section{DISCUSSION}

The current study found no significant age and gender association with the severity of OSMF. However daily frequency of eating areca nut and degree of mouth opening showed significant association. Significant consumption differences were found between younger age subjects and their elder counterparts as youngsters seemed more likely to consume sweetened, packaged, areca nut on a routine basis. The majority of subjects used commercially available, packaged, areca nut followed by consumption of areca nut in other combinations and forms, like betel quid or gutka, mainpuri etc.

Literature review of age and gender distribution has shown wide variations in the occurrence of OSMF. In the current study gender and age group distribution for clinical grading of OSMF showed non-significant deviation similar to the findings of Reddy et $\mathrm{al}^{21}$ and Chatuvedy et $\mathrm{al}^{22}$ from India and an earlier study conducted by Sirsat and Khanolkar ${ }^{23}$ which put the male:female ratio at 1:1. However Wahi et al. ${ }^{24}$ had reported a male to female ratio of 2:1 as did Shah and Sharma ${ }^{25}$ in who reported a male to female ratio of 1.8:1.

A male predominance was reported by Sinor et $\mathrm{al}^{26}$ with men showing a statistically significant increase in gutka and kharra/ mawa chewing habits. In the studies where males dominated it was noted that they used gutka and similar products more because of easy availability whereas females being more conscious about their health and esthetics, possibly were more reluctant to purchase them. This could be one of the reasons responsible for a high male to female ratio. However some epidemiological surveys in India have also shown a female predominance. ${ }^{27}$ Compared to men, women have shown statistically significant predilections for exclusive areca nut chewing habits; mainly attributable to local cultural practices. These studies have controversial findings with male being predominant in some and women in others. Again, this may be due to small sample sizes or to demographic and cultural variations. The current study overcomes these limitations with a single investigator and a larger sample size across different settings: public and private. It has been noted that cultural trends among the Pakistani population are changing, with females increasingly outgoing as well as economically supporting and helping in family needs thus also increasing their exposure to different eating and chewing habits.

It is well-documented that as the severity of OSMF increases there is a progressive inability to open the mouth associated with varying degrees of restriction in tongue movements. In the current study statistically significant association was found 
between increasing severity of OSMF with decrease in mouth opening. This is in accordance with the findings of Kiran Kumar et $\mathrm{al}^{27}$ and might be due to the fact that the majority of our patients were reported for treatment only after the onset of restricted mouth opening.

The duration of chewing years had insignificant association with severity of OSMF. However, the daily consumption frequency was significant with individuals consuming more than 5 packets per day showing increased severity. Subjects who consumed less than five packets per day had grade I and grade II OSMF. This direct relationship of frequency with severity of OSMF grading is consistent with the findings of Reddy et al. ${ }^{21}$

More than two thirds of this study population that consumed areca nut were in their second and third decades which is in concordance with Borle and Borle. ${ }^{28}$ Similarly, Sinor et al. ${ }^{26}$ reported that more than three fourths of OSMF cases were under the age of 35 years with the maximum in the 25 to 44 years age group. Shah and Sharma ${ }^{25}$ in their study from Delhi also reported the majority of their cases to be in the 21 to 40 years age group. Traditionally, in India and Pakistan, only married adults have been consumers of areca nut products. The reasons for increased consumption by youngsters include ease of availability at school canteens, confectionary shops and from friends. These products are cheap, colorfully packaged, often sweetened and conveniently carried thus increasing their attraction. In addition, there is no age restriction on sale.

Areca nut is consumed fresh or in dry forms: cured by sun-drying, baking or roasting. The most preferred forms are commercially manufactured dry areca mixtures that are convenient and less perishable. In the current study more than half of the sample consumed commercially available areca nut, with the majority preferentially consuming one specific brand (brand A). It is well documented that the major constituents in packaged areca nut combinations are carbohydrates, fats, proteins, crude fibre, polyphenols (flavonols and tannins), alkaloids and mineral matter. Polyphenols (flavonols and tannins) constitute a large proportion of the dry weight of the nut and are responsible for the astringent taste. They contain at least 9 structurally related pyridine alkaloids including arecoline, arecaidine, arecaine, arecolidine, guvacine, isoguvacine, guvacoline, and coniine; all of which have important stimulating effects. ${ }^{8.29}$ A detailed chemical analysis of $(n=36)$ different commercially available brands of Pakistani and Indian origin by Arayne (1998) confirmed the presence of diacetyl morphine (heroin) in some of the samples. Similar studies need to be conducted on some products in the present study to determine why they are preferentially consumed. ${ }^{30}$
In our study, betel quid with tobacco or variants, like gutka and mawa; betel quid without tobacco; areca nut used alone, were found to be statistically significant in severity of clinical grading of OSMF. This attributes to the fact that commercial products are concentrated; are freeze dried; and have a higher dry weight concentration of pathology causing irritants in comparison to the traditionally prepared home-made betel quid. Another factor supporting this could be that the antioxidant capabilities of betel quid (paan) leaf, known to be rich in beta-carotene with the capacity to quench mutagenic free radicals, may counteract the different pathology causing irritants. ${ }^{30-32}$ Dried forms of tobacco are more easily absorbed by oral mucosa and could increase the tendency to dependence. ${ }^{33}$

Oro-pharyngeal cancer is associated with increased consumption of tobacco and areca nut both of which are major risk factors for significantly increasing the comprehensive burden of cancer. The International Agency for Research on Cancer recently confirmed the carcinogenic potential of smokeless tobacco. Habitual consumption of areca nut is also associated with various nutritional deficiencies which themselves act as independent potential carcinogens. Oral cancer largely can be prevented through control of the risk factors. The WHO global oral health programme aims atoral cancer prevention through experiences from assimilated approaches in prevention and health promotion. It also promotes the development of global scrutiny systems for the screening of oral cancer and related risk factors. ${ }^{34}$ Statistics reflecting the increase in incidence and mortality of oral cancer (ICD-10: C00-C08) are stored in the Global oral Health Data bank. On the basis of this in 2007 the World Health Assembly passed a resolution stressing on prevention of oral cancer for the first time in 25 years. ${ }^{35}$

The sheer volume of oral cancer and the costs associated with curative treatments make prevention the only viable option. Health organizations along with governments around the globe are taking steps to increase awareness related to risk associated with consumption of areca nut. In 2012, the WHO released an action plan calling for a combination of policy, public awareness campaigns, and community outreach to control the practice. With an increase in the rate of oral cancer around the globe, reduction of risk factors is essential for public health safety. ${ }^{35}$

More than half of the study population showed a high frequency of using packaged areca nut: the majority preferring specific brands. The rest consumed betel quid with tobacco and other derivatives or betel quid without tobacco. Severity in grading of OSMF is significantly associated with frequency of consumption. Statistically significant reduction in mouth opening correlated 
with severity of clinical grading. Furthermore, an interesting finding of a statistically significant difference was revealed between areca nut alone, betel quid with tobacco and its derivatives and betel quid without tobacco in the progression of clinical grading of OSMF.

It is alarming that more than two thirds of subjects, in a younger age group, chewed areca nut. However as age increased the subjects were found to be more attracted to consuming areca nut derivatives in the form of betel quid with or without tobacco. With a global recognition of the role of prevention over treatment it is imperative that developing countries, especially those with large oral cancer burdens declare OSMF as a public health problem and direct their energies and resources towards prevention. It is recommended that community oriented outreach programs on oral health awareness to be developed, emphasizing children who represent the upcoming future, to avoid/quit areca nut and its derivatives. This includes a primordial mode of prevention: that of changing life style. To reinforce the message susceptible populations also should be aware of OSMF's high risk of malignant transformation and poor prognosis leading to a painful death in majority of the cases.

\section{ACKNOWLEDGMENTS}

We are grateful to Dr. Musarrat Adnan for proof reading and making valuable editing suggestions for this article.

\section{CONFLICTS OF INTEREST}

No potential conflicts of interest were disclosed.

\section{REFERENCES}

1. Schwartz J. Atrophia idiopathica mucosa oris. Presented at the 11th International Dental Congress, London, UK, 1952.

2. Pindborg JJ, Sirsat SM. Oral submucous fibrosis. Oral Surg Oral Med Oral Pathol 1966;22:764-79.

3. Rajendran R. Oral submucous fibrosis: etiology, pathogenesis, and future research. Bull World Health Organ 1994;72:985-96.

4. Meghii S, Warnakulasuriya S. Oral submucous fibrosis: an expert symposium. Oral Dis 1997;3:276.

5. Paymaster JC. Cancer of the buccal mucosa; a clinical study of 650 cases in Indian patients. Cancer 1956;9:431-5.

6. Arakeri G, Brennan PA. Oral submucous fibrosis: an overview of the aetiology, pathogenesis, classification, and principles of management. Br J Oral Maxillofac Surg 2013;51:587-93.

7. Murti PR, Bhonsle RB, Pindborg JJ, Daftary DK, Gupta PC, Mehta FS. Malignant transformation rate in oral submucous fibrosis over a 17-year period. Community Dent Oral Epidemiol 1985;13: 340-1.
8. Mathew P, Austin RD, Varghese SS, Kumar M. Role of areca nut and its commercial products in oral submucous fibrosis-a review. J Adv Med Dent Sci Res 2014:2:192-200.

9. Bhat SJ, Blank MD, Balster RL, Nichter M, Nichter M. Areca nut dependence among chewers in a South Indian community who do not also use tobacco. Addiction 2010;105:1303-10.

10. Gupta VK, Malhotra S, Patil R, Tripathi A. Oral submucous fibrosis at pediatric age, now time to think: series of two cases. Indian J Med Paediatr Oncol 2013;34:107-10.

11. Dhariwal R, Ray JG, Pattanayak SM, Swain N. Oral submucous fibrosis: a report of two pediatric cases and a brief review. J Indian Soc Pedod Prev Dent 2012;30:85-8.

12. Bhonsle RB, Murti PR, Daftary DK, Gupta PC, Mehta FS, Sinor PN, et al. Regional variations in oral submucous fibrosis in India. Community Dent Oral Epidemiol 1987;15:225-9.

13. Auluck A, Rosin MP, Zhang L, Sumanth KN. Oral submucous fibrosis, a clinically benign but potentially malignant disease: report of 3 cases and review of the literature. J Can Dent Assoc 2008;74: $735-40$.

14. Tilakaratne WM, Klinikowski MF, Saku T, Peters TJ, Warnakulasuriya S. Oral submucous fibrosis: review on aetiology and pathogenesis. Oral Oncol 2006;42:561-8.

15. World Health Organization. International Agency for Research on Cancer (IARC). IARC monographs on the evaluation of carcinogeneic risk of chemicals to humans. Lyon, IARC Press, 1985.

16. Gupta PC, Warnakulasuriya S. Global epidemiology of areca nut usage. Addict Biol 2002;7:77-83.

17. Shah S, Qureshi R, Azam I. Is Chaalia/Pan Masala harmful for health? practices and knowledge of children of schools in Mahmoodabad and Chanesar Goth, Karachi. J Pak Med Assoc 2009;59: 550-4.

18. Ali SM, Qureshi R, Jamal S. Prevalence of oral submucous fibrosis and use of tobacco and related products amongst school going males. Pak Oral Dent J 2013;31:384-7.

19. Khan MA, Siddqui HK, Hasan T, Bashir S. Prevalence of areca nut eating habits and incidence of oral submucosal fibrosis in schoolchildren. A prospective cross-sectional survey. Pak Oral Dent J 2014:34:462-6.

20. Bose T, Balan A. Oral submucous fibrosis-A changing scenario. J Indian Acad Oral Med Radiol 2007;19:334-40.

21. Reddy V, Wanjari PV, Banda NR, Reddy P. Oral submucous fibrosis: Correlation of clinical grading to various habit factors. Int J Dent Clin 2011;3:21-4.

22. Chatuvedi VN, Sharma AK, Chakrabarati S. Salivary coagulopathy and humoral response in oral submucous fibrosis (OSMF). J Indian Dent Assoc 1991;62:51-3, 59

23. Sirsat SM, Khanolkar VR. Submucous fibrosis of the palate and pillars of the fauces. Indian J Med Sci 1962;16:189-97.

24. Wahi PN, Kapur VL, Luthra UK, Srivastava MC. Submucous fibrosis of the oral cavity. 2. Studies on epidemiology. Bull World Health Organ 1966;35:793-9.

25. Shah N, Sharma PP. Role of chewing and smoking habits in the etiology of oral submucous fibrosis (OSF): a case-control study. J Oral Pathol Med 1998;27:475-9.

26. Sinor PN, Gupta PC, Murti PR, Bhonsle RB, Daftary DK, Mehta FS, et al. A case-control study of oral submucous fibrosis with special reference to the etiologic role of areca nut. J Oral Pathol Med 1990;19:94-8.

27. Kiran Kumar K, Saraswathi TR, Ranganathan K, Uma Devi M, 
Elizabeth J. Oral submucous fibrosis: a clinico-histopathological study in Chennai. Indian J Dent Res 2007;18:106-11.

28. Borle RM, Borle SR. Management of oral submucous fibrosis: a conservative approach. J Oral Maxillofac Surg 1991;49:788-91.

29. Murti PR, Gupta PC, Bhonsle RB, Daftary DK, Mehta FS, Pindborg JJ. Effect on the incidence of oral submucous fibrosis of intervention in the areca nut chewing habit. J Oral Pathol Med 1990; 19:99-100

30. Arayne MS, Sultana N, Abaidulla. Narcotic adulteration in fennel and beetle nuts (Saunf Supari). Presented at the Ninth National Chemistry Conference, Karachi, Pakistan, December 6-8, 1998.

31. Babu S, Bhat RV, Kumar PU, Sesikaran B, Rao KV, Aruna P, et al. A comparative clinico-pathological study of oral submucous fibrosis in habitual chewers of pan masala and betelquid. J Toxicol Clin
Toxicol 1996:34:317-22.

32. Stich HF, Mathew B, Sankaranarayanan R, Nair MK. Remission of oral precancerous lesions of tobacco/areca nut chewers following administration of beta-carotene or vitamin $\mathrm{A}$, and maintenance of the protective effect. Cancer Detect Prev 1991;15:93-8.

33. Avon SL. Oral mucosal lesions associated with use of quid. J Can Dent Assoc 2004; 70:244-8.

34. Petersen PE. Tobacco and oral health: the role of the World Health Organization. Oral Health Prev Dent 2003;1:309-15.

35. World Health Assembly. World Health Organization Oral Health: action plan for promotion and integrated disease prevention (60th World Health Assembly resolution A16), Genveva, WHO, 2007. 